Becquerel's and Lippmann's Colour Photographs.

THE point raised by Prof. Meldola (p. 28) is partially, if not completely, answered by Otto Wiener in a most valuable paper, "Ueber Farbenphotogranhie durch Körperfarben, und Mechanische Farbenanpassung in der Natur," published in Wiedemann's Annalen, 1895, 1v, 225-28r. Wiener devised a method of examining colour photographs through a right-angled prism in such a way that pigment colours, which owe their hues to absorption, are distinguished from interference colours by not changing their positions when seen through the prism. The application of this method to colour photographs by Lippmann's process and the older processes of Seebeck, Poitevin and Becquerel, shows that in Lippmann's photographs the colours are due entirely to interference. In Becquerel's process they are due mainly to interference, though pigment colours are formed to an extent which is generally very small, but which increases with the duration of the exposure. The colours on Becquerel plates do change with the angle of incidence, though the changes are very small, probably in consequence of the high refractive power of the film. Further, when the film is examined from the back the colours do not occupy the same positions as when they are viewed from the front. It follows that the colours on Becquerel plates are due essentially to the same cause as those on Lippmann's plates, and the theory of standing waves is applicable in both cases.

With the processes of Seebeck and of Poitevin, on the other hand, the colours are exclusively pigment colours, and the theory of standing waves is not applicable.

Weston-super-Mare, May 16.

C. H. Bothamley.

\section{Influence of Terrestrial Disturbances on the Growth of Trees.}

IN reply to the note of Mr. H. J. Colbourn on "Influences of Terrestrial Disturbances on the Growth of Trees," in your issue of April 23, allow me to say that his ingenious suggestion of connecting a zone of narrow rings in a section of Douglas spruce with some supposed terrestrial disturbances occurring about the same time, is hardly tenable, even if the coincidence of the two phenomena were established, which seems not to be the case. The occurrence of a zone of narrow rings is common in all our trees, and I have observed it most frequently in all southern pitch pines, which are rarely over three hundred years old, and hence outside of the possibilities of the influence of unknown or uncertain terrestrial disturbances.

The suddenness with which the rings become narrow and then again wide, described by Mr. Colbourn, and observed by us in many other trees, is, to be sure, puzzling ; nevertheless, we cannot escape the conclusion that it is due to changes in the conditions surrounding the tree. Yet it is not necessary that the change of conditions and of ring-width should be simultaneous, that is to say, the change of conditions may have occurred without having been immediately responded to by the growth of the tree.

The following explanation may serve as a type. Let a tree grow up under favourable conditions for a hundred years, as the Douglas spruce in question seems to have done, when its ring. growth will be wide, its crown reaching above its neighbours. A hurricane breaks off a large part of its crown, when necessarily and suddenly, at least within a year, the rings become narrow in proportion. Within the next thirty years the crown recuperates, which in a resinous conifer like the Douglas spruce is possible without fear of fungus attacks and decay; but the food-material descending from the foliage will for a long time be only sufficient, on the particular section in question at the base of the tree, to make the narrow annual ring, even after the crown is fully recuperated. Were a section cut higher up in the tree, it would be found that the rings there have begun to widen sooner than at the lower section. Finally, and rather suddenly for any given section, the supply has become normal, and especially if an exceedingly favourable season occurs at the same time the rings show again normal width.

The same sudden change from narrow to wide rings is observed when a tree oppressed by its neighbours is suddenly relieved by windfall or by man's interference from its oppressors; but the response even then is not simultaneous, it takes one or more years before the crown is in condition to utilise the full amount of light at its disposal, and to furnish food to all parts of the tree in increased ratio.

Washington, D.C., May I I.

B. E. FERNOW.

NO. I 387 , vOL. 54

\section{Our Bishops and Science.}

THE friends of both science and religion will thank you warmly for publishing the Bishop of Ripon's public testimony to Huxley's spirit of sincerity and love of truth. It is the more timely because of your recent strictures upon the Bishop of London. May I therefore, as a country parson, with an equal love for scientific integrity and religious truth, suggest to the readers of those strictures in NATURE (p. 607, April 30) that probably Bishop Temple has been misunderstood. I am sure it is not fair to his spirit to put into his mouth, "Away with all these abominations. Purge the elementary schools of everything scientific, and substitute dogmas and subjects more fitted to the stations of life in which it has pleased God to call the scholars."

Is it not more likely that the real clue is in the sentence quoted about "instructing little children in elementary schools in a great many scientific subjects?" For many earnest educationalists have, as friends of science, spoken strongly on the evils of the cramming of bits of science subjects and "stages" by crudely crammed "Government certificated" "science" teachers cramming large classes for grants on " passes" to butter their bread.

In any case, the true views of the great bishop will be found in his "Bampton Lectures" for 1884 , on the relations between science and religion; and the last Quarterly Reviewe, on G. J. Romanes, contains an eminent example of the reverent treat. ment of both.

I will frankly add that I do not think your quotations from $\mathrm{Mr}$. Mundella's address can be too widely known among the bishops and clergy who have such influence with the laity. Agricultural pursuits suffer more from our ignorance than our want of money; and agricuitural science cannot be widely taught until the elementary principles of chemistry and physics are diffused in our villages.

On this subject we have also had the weighty testimony of Mr. Gladstone. The voting of money for light railways and such objects is a quack remedy. The fact is that true educational enthusiasts who will think first of our children, and be generous to them first, have hitherto been appallingly scarce in the House of Commons and its parties.

Nor is even the geographical significance of our need of science education likely to be perceived by the majority, if, as is stated in the Anti-Slavery Reporter (March-April 1896, p. 80), two M.P.s can stand before a map of South America in the map room of the House of Commons, and dispute with one another as to where Egypt was to be found on that map. However matters are mending, we hope.

Crowell, Oxon, May I 5.

\section{Blood-Brotherhood.}

THERE are good reasons why this ancient custom can never be a preventive of disease, though sometimes it may be a cause of it. The serum treatment has been found useful, and presumably will be found useful only in such diseases or diseased conditions as are due to poisons (toxins) secreted by various species of pathogenic micro-organisms (e.g. those of rabies, anthrax, diphtheria), or by some animals (e.g. scorpion, snake), as weapons of offence or defence.

As regards certain zymotic diseases (e.g. small-pox, scarlatina, syphilis), it is known that one attack confers more or less complete immunity against subsequent attacks; that is, the micro-organisms of these diseases are, after the recovery of the host, unable to persist and produce their toxins in him ; and this for the reason that during his illness certain of his body cells, known as phagocytes, become inured to the toxins, and are thus enabled to attack and destroy the micro-organisms producing them. When the phagocytes fail to become inured, the microorganisms continue to produce these toxins, and the host perishes, poisoned by them. Now the toxins produced by the micro-organisms of most zymotic diseases are not always of the same degree of virulence, and when they are feeble the phago. cytes the more easily become inured to them, and destroy the micro-organisms; and not only do they do so, but this preliminary training enables them, when attacked by more virulent micro-organisms of the same species, i.e. of the same disease, to react to the stronger toxins of these also, and again destroy the micro-organisms. Man has taken advantage of this fact to artificially lower or "attenuate" the virulence of various species of pathogenic micro-organisms (e.g. those of anthrax an 